\title{
DIGITAL DOCUMENTATION'S ONTOLOGY: CONTEMPORARY DIGITAL REPRESENTATIONS AS EXPRESS AND SHARED MODELS OF REGENERATION AND RESILIENCE IN THE PLATFORM BIM/CONTAMINATED HYBRID REPRESENTATION
}

\author{
Alessandro De Masi \\ Brera Academy of Fine Arts Milan, Department of Design and Applied Arts, Milan, Italy, alessandro.demasi@ unina.it, orcid.org/0000-0003-3433-2583
}

KEY WORDS: Digital Documentation's Ontology, Contaminated Hybrid Representation, Computational Representation, Digital Morphology, Digital Lexicon, Digital Metamorphosis, Digital Regeneration, Digital Interaction and Sharing

\begin{abstract}
:
The study illustrates a university research project of "Digital Documentation's Ontology", to be activated with other universities, of an Platform (P) - Building Information Modeling (BIM) articulated on a Contaminated Hybrid Representation (diversification of graphic models); the latter, able to foresee categories of Multi-Representations that interact with each other for to favour several representations, adapted to a different information density in the digital multi-scale production, is intended as platform (grid of data and information at different scales, semantic structure from web content, data and information storage database, archive, model and form of knowledge and ontological representation shared) of: inclusive digital ecosystem development; digital regenerative synergies of representation with adaptable and resilient content in hybrid or semi-hybrid Cloud environments; phenomenological reading of the changing complexity of environmental reality; hub solution of knowledge and simulcast description of information of Cultural Heritage $(\mathrm{CH})$; multimedia itineraries to enhance participatory and attractive processes for the community; factor of cohesion and sociality, an engine of local development. The methodology of P-BIM/CHR is articulated on the following ontologies: Interpretative and Codification, Morphology, Lexicon, Syntax, Metamorphosis, Metadata in the participatory system, Regeneration, Interaction and Sharing. From the point of view the results and conclusion the study allowed to highlight: a) Digital Regenerative synergies of representation; b) Smart CH Model for an interconnection of systems and services within a complex set of relationships.
\end{abstract}

\section{INTRODUCTION}

\subsection{Objectives}

The study illustrates a university research project based on "Digital Documentation's Ontology" or better named as "Digital Transformation Ontology post-COVID-19" in the documentation process and knowledge's representation; this is due to the prevailing and widespread multimedia connected to the new roles that are also the result of post-COVID-19 (SARS-CoV-2) digitization. Therefore, the study will allow:

1. to describes, in an innovative way, "set of models, contents, categories, classes, and relationships" involved in the process and afferents to a domain;

2. to organize the "Limit of Knowledge's Representation" on the basis of the way in which the diversified information interact with each other, creating "reciprocal relations";

3. to create an efficient "semantic structure with web contents", that groups different types of information. All that through the study of meanings and the relative common understanding of the meaning of things;

4. to design a data and information storage database based on a "common set of terms used" to describe the information;

5. to favor new digital lexicon easy to understand of transmission of architectural contents; in addition, represent model of rapid succession of the changes occurring in the time;

6. to favor "digital content design solutions" in "hybrid or semi-hybrid cloud environments" (public and private clouds) for the spread of "cloud computing"; in particular, extraction, grouping and sharing of resources, through links to different management levels;

7. to favor "shared multimedia itineraries to enhance participatory and attractive processes" intended as a factor of cohesion and sociality, an engine of local development for the community.

It can be activated with other universities and based on a Platform (P) - Building Information Modeling (BIM) connected to a service integration host for data communication to professionals and users; it is articulated on different layers of the Contaminated Hybrid Representation (CHR) with reference to both the European regulations (Agenda 2030) and the National - Regional ones including the National Recovery and Resilience Plan (PNRR): Next Generation Italia; without considering the Urban and Territorial Regeneration regulations which aim to create applications of "Smart Cultural Heritage". The platform and in particular the CHR aims to represent: a) the architecture and its space with the communication of modification processes occurring in time (that have contaminated the environment); b) the complicated and provocative sculptural forms for the different organizational systems present. In particular, architectural composition and the landscape; c) multiplicity and irregular of the surfaces lines and the matrix search; d) the cultural and social dynamics of the contemporaneity. The CHR is called "hybrid" because it is able to foresee categories of Multi-Representations (MR) that interact with each other for to favour several representations, adapted to a different information density in the digital multiscale production (Interpretative and Codification, Morphology, Lexicon, Syntax, Metamorphosis, Metadata in the participatory 
system, Regeneration, Interaction and Sharing); it based on:

- De-Morphogenesis, understanding as deconstruction of the architectural and Landscape image (De Masi, 2020a); in addition, On-Morphogenesis, subsequent reconstruction of the formal architectural (De Masi, 2020a) and Landscape vocabulary within a new vision of transformation;

- Computational Representation (CR), understood as innovative communication of the diversification of $3 \mathrm{D}$ graphic models for the empty spaces of the new scenic contexts; this to favor: a) recovery and resilience of the urban landscape form (understood as territories); b) visual representation of models (understood as space and content) with simultaneous description of information for the architecture and urban landscape;

- Digital Regeneration (DR) of the visual field of the urban landscape with the reconnection of empty spaces to the Cultural Heritage $(\mathrm{CH})$ and, therefore, of the surrounding area with the related visual scenic fields; in addition, participatory and attractive processes due to the historical significance that they represent for the community: of cohesion and sociality, an engine of local development for the recovery of building heritage;

With this premise the P-BIM/CHR is intended as:

1. "Data and Information Grid at different scales (3D / 2D viewer)" relevant and afferents to a domain to highlight "traces of knowledge and limits of knowledge";

2. "Semantic structure from web content", divided by pages, with the aim of grouping types of information, sets of models, classes and relationships involved in the process and afferents to a domain;

3. "Structuring and semantic decomposition of digital elements" through aspects of semantic recognition based on geometric, cultural, morphological, constructive and structural classification;

4. "Data and Information Storage Database" based on a "common set of terms used" to describe information and facilitate efficient communication;

5. "Archive", a domain reference ontology of general and complex value of graphic and documentary representations; this through syntax (formal relationship) and contemporary digital lexicon explained with Evolutionary and NonEvolutionary knowledge for the representation of pattern relating to modern and ancient $\mathrm{CH}$ /Cultural Landscape;

6. "Model and Form of Knowledge and Ontological Representation Shared" for information systems and in particular for the Semantic Web in order to insert entities and their relationships; in particular, it allows sharing of project files and metadata with relative data organization (Figure 1).

From the point of view of relevance, the study allow to highlight:

- a Digital ecosystem for structuring a digital, inclusive society based on digital tools and skills; the "Cloud Architect" will represent the professional figure for the experimentation and evaluation of digital skills and systems. In this context, the Schools of Architecture will soon have to deal with the evolution of the growing digital society in which components, digital languages and procedures interface;

- Digital regenerative synergies of representation for a new digital culture based on scalable, adaptable and resilient digital content in hybrid or semi-hybrid Cloud environments. This is achieved through links to various management levels to respond to digital transformations;
- Smart CH model for an interconnection of systems of assets and services within a complex set of relationships;

- Phenomenological reading of the changing complexity of environmental reality through phenomenological approaches to urban, natural, central, shared, cultural, social, empty spaces, also abandoned. This is based on the theories of Kevin Andrew Lynch (1918-1984) and on the application of analytical-interpretative criteria to the urban environment for the evaluation of quality;

- Hub solution of knowledge and simulcast description of information of $\mathrm{CH}$ connected to a service integration host. This through Digital Layout divided by category (type, reference, geometry and shape, visual appearance, dimensions and properties) in order to obtain: a) Exchange of multidimensional information; b) Transition from parametric representations to objects integrated into 3D Web; c) Creation of 3D elements by geometry, semantic representation and appropriate correspondence;

- Manipulation of intrinsic (dimensional, geometric, morphological and chromatic) and extrensic data;

- Multimedia itineraries to enhance participatory and attractive processes for the community; understood as a factor of cohesion and sociality, an engine of local development.

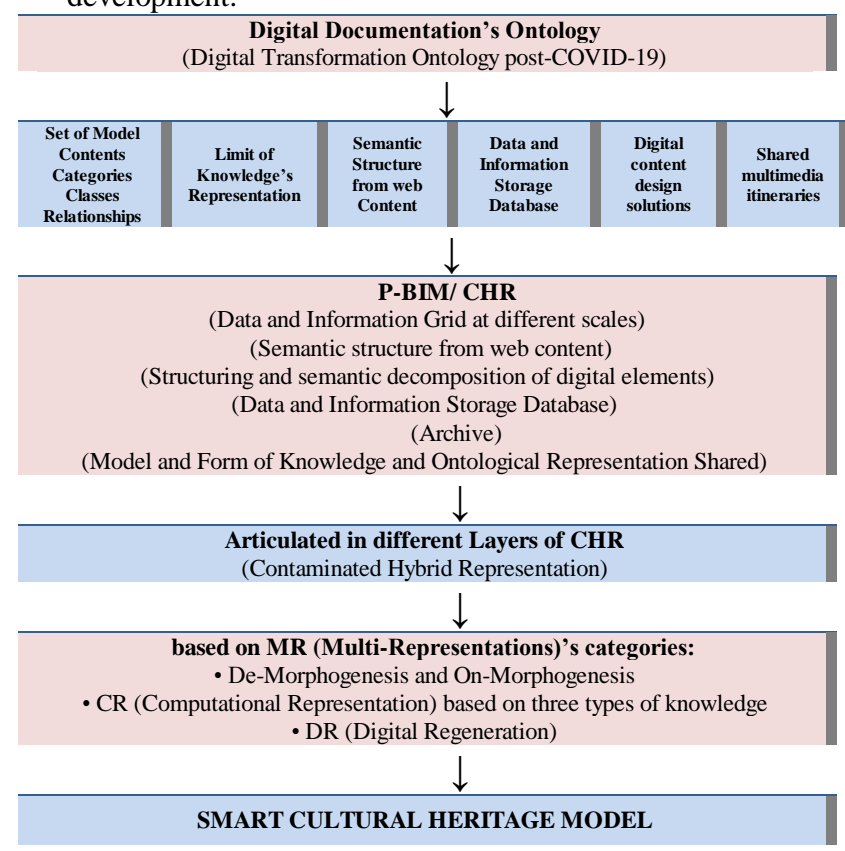

Figure 1. Digital Documentation's Ontology Structuring.

\section{MAIN BODY}

\subsection{Research Methodology}

The P-BIM/CHR is implemented through Autodesk's A360 and BIM 360 (European Union Public Procurement Directive 2014/24/UE); in particular, connected to a service integration host for data communication to professionals and users with dynamic characteristics. It is based on the following ontologies (Figures 2, 3):

DIC. Digital Interpretative and Codification, understood as criteria and conditions for evaluation of $\mathrm{CH}$ Assets, according the Guidelines on $\mathrm{CH}$ (European Union, Council of Europe, 2012);

DM1. Digital Morphology, understood as the study of the "grammar of formal composition" and of the formal structure 
with the relative categories of classification and belonging. It is divided into De-Morphogenesis and On-Morphogenesis;

DLx. Digital Lexicon, understood as a set of determining and therefore structuring elements for the constitution of the form at different levels; in particular, through the identification of rules and relationships between the components articulated on $\mathrm{CR}$;

DS1. Digital Syntax, understood as a study of the rules or relationships that structure the shape to determine the placement of the elements;

DM2. Digital Metamorphosis intended as "Digital Resilience Measurement Model" to detail the "Limit of Resilience" in the knowledge;

DM3. Digital Metadata in the participatory system of description of the data set to promote transparency in the professional field;

DR. Digital Regeneration of the urban landscape with the reconnection of empty spaces to the $\mathrm{CH}$;

DS2. Digital Interaction and Sharing, understood as relationship between augmented reality (AR) and artificial intelligence (AI). The most significant ontological classifications are reported below.

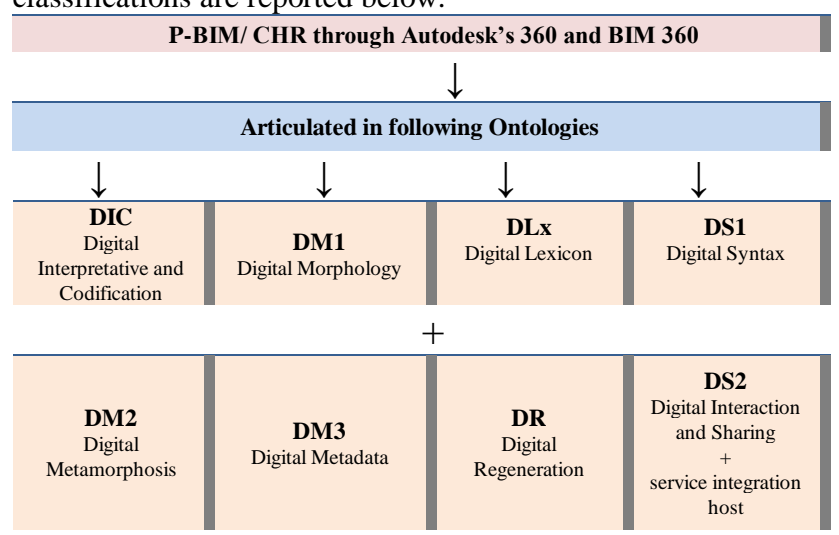

Figure 2. P-BIM/CHR Methodology.

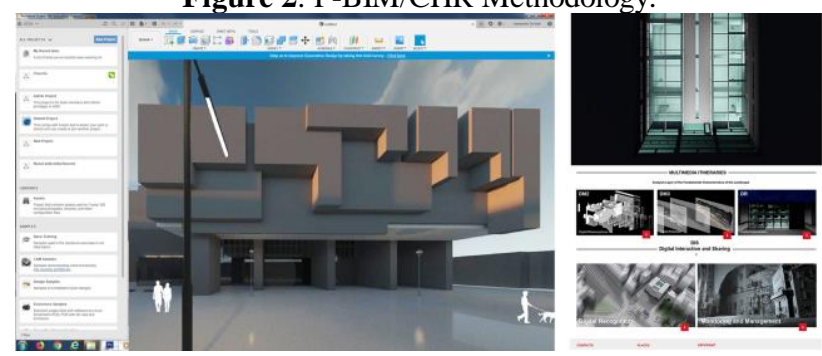

Figure 3. From left, New Bocconi University headquarters in Milan - Grafton building (2008); Casa del Fascio, Terragni (1936). Cloud Computing Platform's Homepage: Autodesk

Fusion 360 and service integration host (A. De Masi).

\subsubsection{Digital Morphology (DM1)}

With regard the formal aspect signs and the study of the forms, the level considers the following categories:

DM1.1 "De-Morphogenesis" understanding as deconstruction of the architectural and Landscape image (formal and constructive aspects) (De Masi, 2019, 2020a); in addition the definition of same elements's meaning following a new vision for proposes advances of interoperable models application (De Masi, 2019, 2020a). It proposes advances in the field of the: a) visual evaluation of the landscape and architecture's morphological features; b) Communication of landscape modification processes for visual-perceptive regeneration as a remedy for urban degradation. Therefore, it is articulated:

DM1.1.1 "Landscape Form" for the recognition of the landscape families; in particular, description of the fundamental characteristics of the landscape and functioning aspects in order to evaluate Entirety, Criticality and Vulnerability with the subcategories:

- "Elements's Identity", with the following layers: Physiotopes (in order to define different types of landscape); Open Space (consisting of open spaces identification); Anthropological Semiology (in order to define infrastructural, settlement, cultural, historical, architectural sign of arrangement, management of the historicized landscape and the articulation of the Urban and Rural Historical Landscapes of the environmental mosaic); Absolute Visualisation (that allows the display of the great lines of the perceptible landscape about the overall set of morphological aspects present) - (De Masi, 2020a); Landscape Apparatus, according Ingegnoli, 1993 is intended as a distinction between human and natural habitats; in particular relating to connective systems (connectivity of landscape elements), resilient systems (elements with resilience), production systems; Areas and Units of Landscape;

- "Morphological's Characters" through the study the forms of the ground, the distance and position of the observer according to Lynch and described by following subcategories: Visual Planes (succession of elements in the space); Visual Cones (distinguished by dimension, depth, orientation); Main reference points (useful elements for orientation and localization); Delimited Visual Scopes (limited and enclosed view) - (De Masi, 2020a) - (Figure 4);

DM1.1.2 "Architectural Forms" with the following subcategories:

- "Monumentality and Complex Forms" with the following layers: plasticity of forms and subtraction of matter; recovery of the perspective space relationships and geometry; architectural - scenographic construction related to theatrical scenic illusionism in which the perspective method has provided the basis of the optical illusion; transparencies and visual illusion in the articulated monumental staircases (De Masi, 2020a);

- "Mathematical Rule and Graduality of Spaces" through: matrix and geometric texture; a system of rules marked by mathematical and proportional relationships based on the circumference and the square (De Masi, 2020a);

- "Syntax Morphological" through: Formal Composition's Analysis (harmony, symmetry / asymmetry, modularity, rhythm, alignment, visual direction, movement, balance, proportion, visual weight, visual unity, visual contrast); Technological structure (Figure 5);

DM1.2 "On-Morphogenesis with Perceptive and Symbolic References" through both a recomposition of the formal architectural vocabulary in a new vision of transformation, and of the intangible aspects linked to the cultural landscape (De Masi, 2019, 2020a).

\subsubsection{Digital Lexicon (DLx)}

The level, with regard to crucial factors, is structured on the following categories elements for the constitution of the form: DLx1 "Computational Representation" based on analytical interpretative knowledge of: 


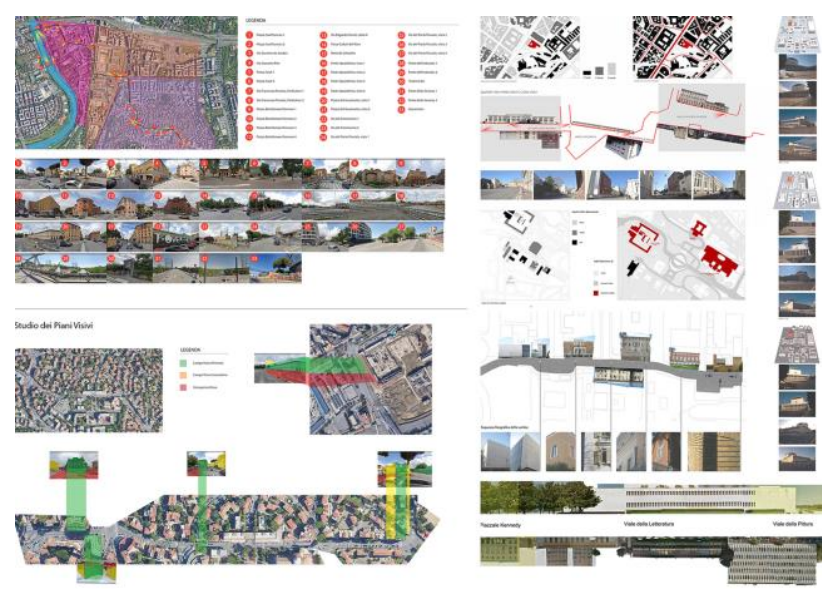

Figure 4. Rome. Study of visual frameworks for recognisability and identity of places, warm and cold tones. University of Rome III and Academy of Fine Art of Rome (A. De Masi)
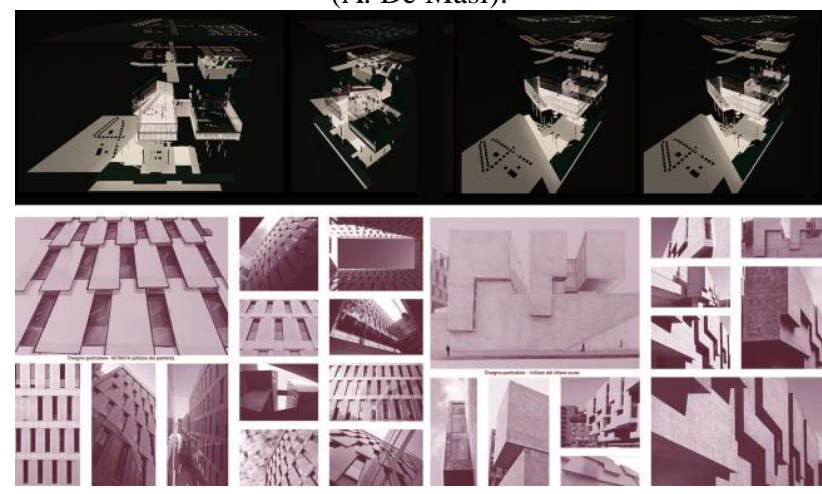

Figure 5. New Bocconi University headquarters in Milan Grafton building (2008). De-morphogenesis of Architectural Forms through "Syntax Morphological". Brera Academy of Fine Arts Milan (A. De Masi).

- "Phenomenological", through the study of categories A (urban, natural spaces) and B (central, cultural, social, empty, abandoned) according to Christian Norberg-Schulz (1926-2000);

- "Geometry" for the study of shapes, of geometric matrices and data search relative at topography, photogrammetry, matching the model and the point cloud. It are applied to the plan and the elevated parts in order to define a one-3D system through experiments of 3D Modeling and Smart tool BIM with the following layers: Survey integration methods based on 3D laser scanner time of flight with Structure from Motion; in particular, photogrammetry of points of interest, meshing of photogrammetry in order to create points of interest, generation of cloud points, compositing of architectural elements, lighting and rendering were performed (Figure 6); 3D acquisition methodology through photogrammetry of points of interest, photogrammetry meshing, cloud point generation, compositing of architectural elements, lighting, rendering (Figure 7); Dialogue between the different methods of analysis and 3D modelling; Algorithmic prototyping methodologies in order to evaluate the potential of the modifications and the changes occurred over time in complex architectures with the functional and performance verification of the architectures;

- "Visual", through information models: Evolutionary knowledge (in their historical becoming) with simulation

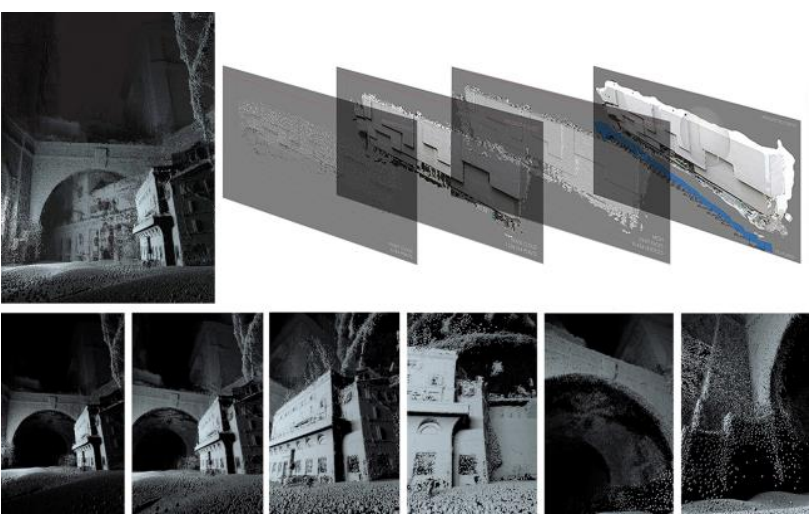

Figures 6, 7. On the top left, historic center of Rome and New Bocconi University headquarters in Milan - Grafton building (2008). Computational Representation, Geometry area: Photogrammetry, photogrammetry meshing, Cloud point generation. Academy of Fine Art of Rome and II School of

Architecture, Polytechnic of Milan (A. De Masi).

lexicon (reconstruction process and digital restitution of horizontal and vertical elements, overlapping data (A. De Masi, 2020). In particular, description of the design matrices and phenomenological reading of the changing complexity of environmental reality (Figures 8, 9); NonEvolutionary knowledge (at a given moment, abstracting from their evolution over time) without lexicon simulation (A. De Masi, 2020) and description of the evolutionary matrices (Figure 10);

- "Resilience" to configure new "models of dynamic representation", not pre-built and above all of recovery for landscape assets; they are the result of the layers of modifications that have occurred over time. They will also be called "resilient models" (territorial development factors) because they will be able to highlight the: a) adversities of landscape complexity; b) positive organizational models of the fundamental characteristics of the new complexity. This in order to systematize environmental information through "thematic systems of families and types" of resilience (aesthetic qualities, phenomenological qualities, quality of use, contextual qualities, quality of meaning) and protective (protective factors for the territory) - (Figures 11, 12);

- "Scalability" to configure multi-scale models of the visual field.

\subsubsection{Digital Syntax (DS1)}

With regard to the rules or relations of structuring the form for an organic position of the elements in the architectural composition, the level considers:

DS1.1 - Interpretative Quality with the subcategories:

- Identity and diversity;

- Continuity and modification of the identity;

DS1.2 - Internal Qualities with the subcategories:

- Connection, Inclusion, Division of the mutation;

- Disintegration and reconstruction of the form;

- Evaluation, Hierarchy;

DS1.3 - External Qualities with the subcategories:

- Cultural models and relational structures;

DS1.4 - Expressive Qualities with the subcategories:

- "Graphic Components" to highlight shape and tonal value, pattern, texture and background through the following 
layers: Chiaroscuro and Chromatic Techniques with connection to the centers of visual attention and to the contrasting elements in a set of regular elements (Figure $13)$;

- "Exaltation of dark tones" to accentuate elongated shadows, as in Giorgio de Chirico's work (1888-1978) (Figure 14);

- "Surfaces and Matter" for the distinction of elements, functional differentiation of spaces, symbolic and psychological meanings;

- "Colour Experimentation" through the layers: a) design combinations Bauhaus 1919-1933 (according to Johannes Itten 1888 - 1967, for chromatic properties - red / white / black - and schemes geometric compositions by subdivision / tripartition, arithmetic and geometric succession, golden section; or as Theo van Doesburg 1883 - 1931, through chromatic contrasts for primary colours or black and white, yellow and black with insertion of coloured elements and multi-coloured objects, strong and contrasting colours, geometric patterns) - (De Masi, 2020a);
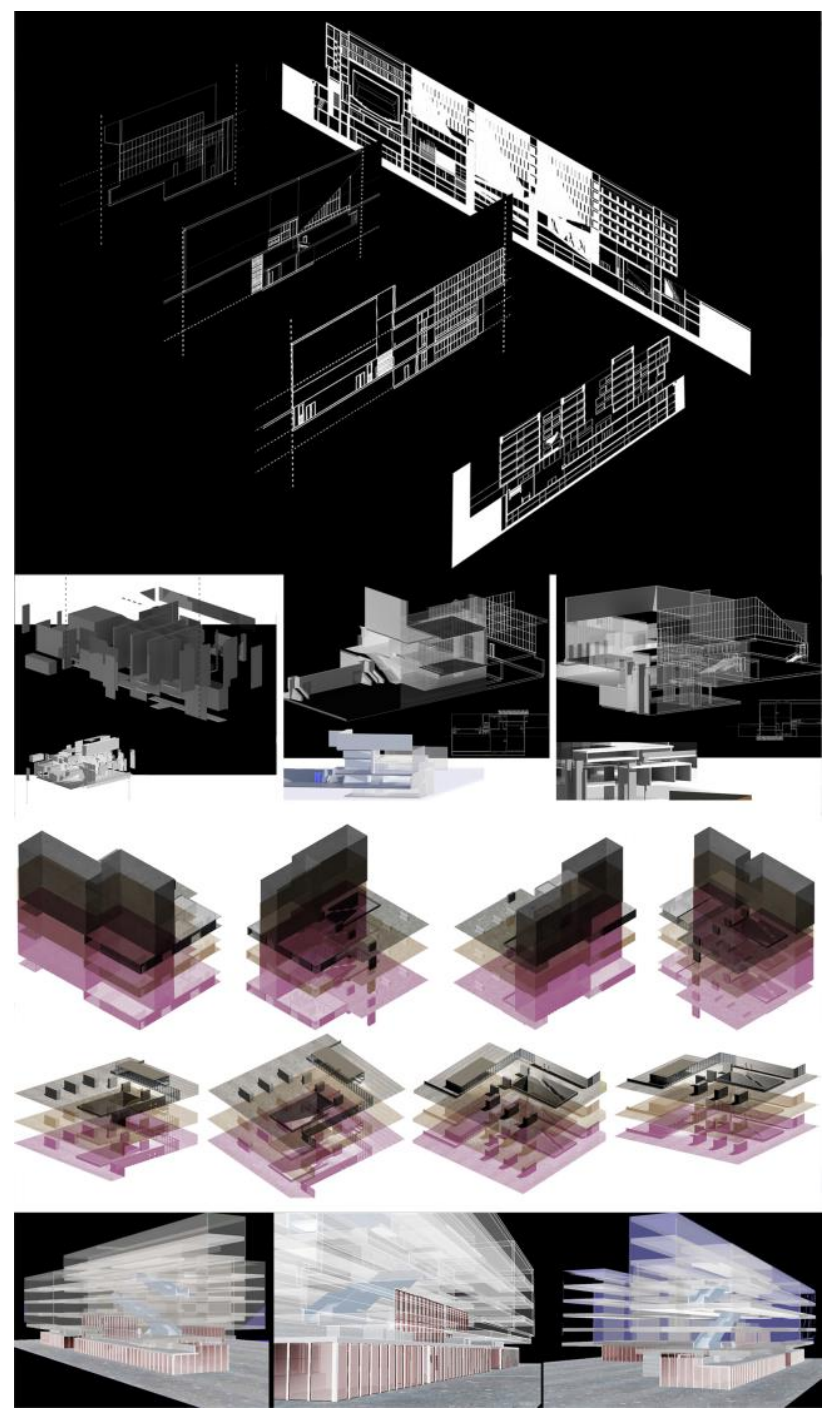

Figure 8. New Bocconi University headquarters in Milan Grafton building (2008). Computational Representation,

Visual area: Evolutionary knowledge. Brera Academy of Fine Arts Milan and II School of Architecture, Polytechnic of Milan (A. De Masi)

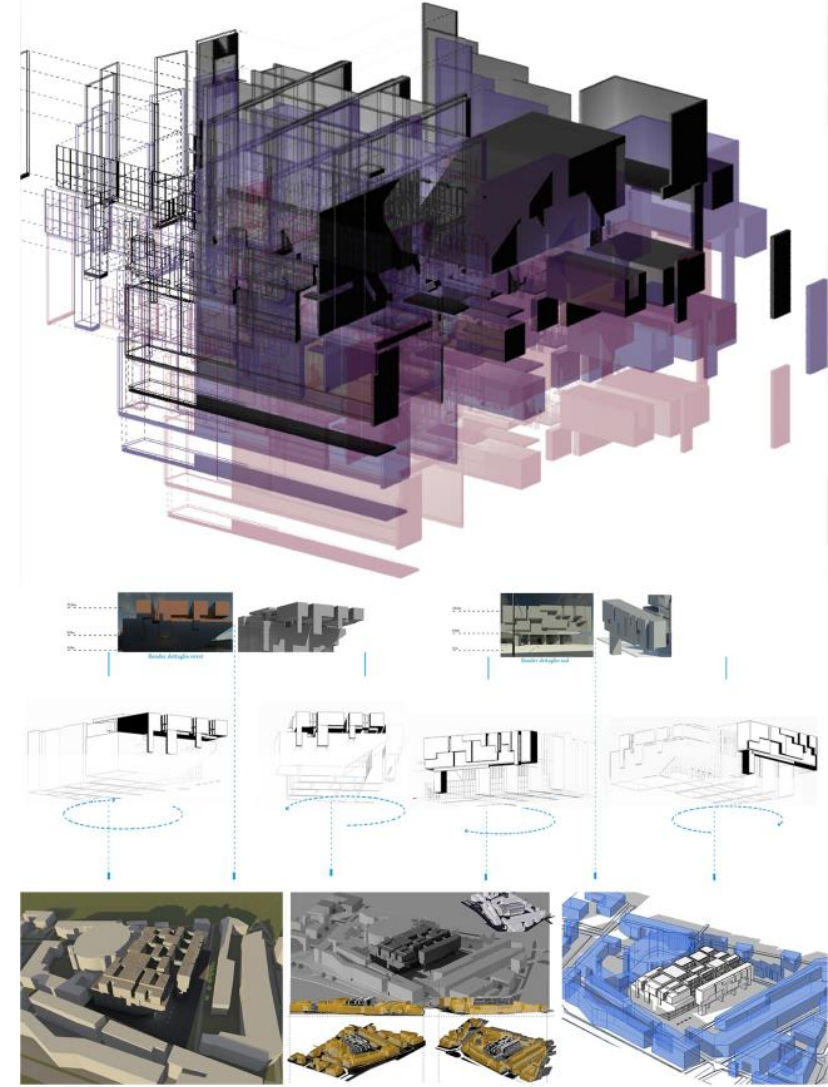

Figure 9. New Bocconi University headquarters in Milan Grafton building in via Röntgen (2008). Computational Representation, Visual area: Evolutionary knowledge. Brera Academy of Fine Arts Milan (A. De Masi).
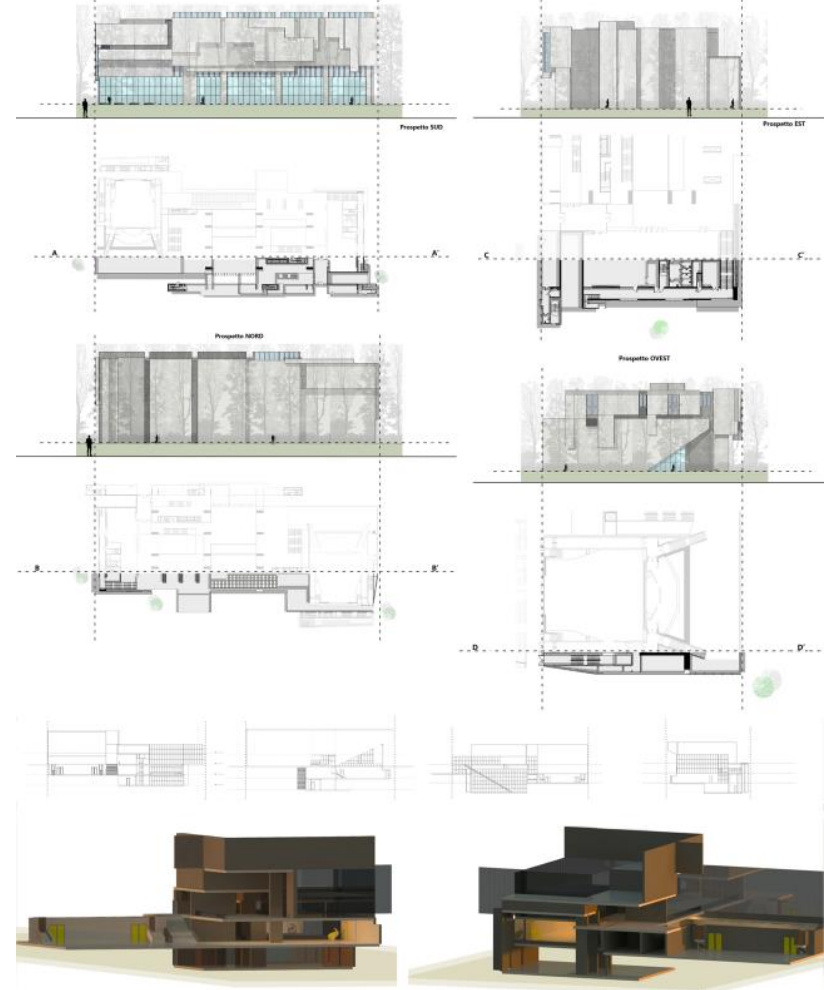

Figure 10. New Bocconi University headquarters in Milan Grafton building in via Röntgen (2008). Computational Representation, Visual area: Non-Evolutionary knowledge. Brera Academy of Fine Arts Milan (A. De Masi). 

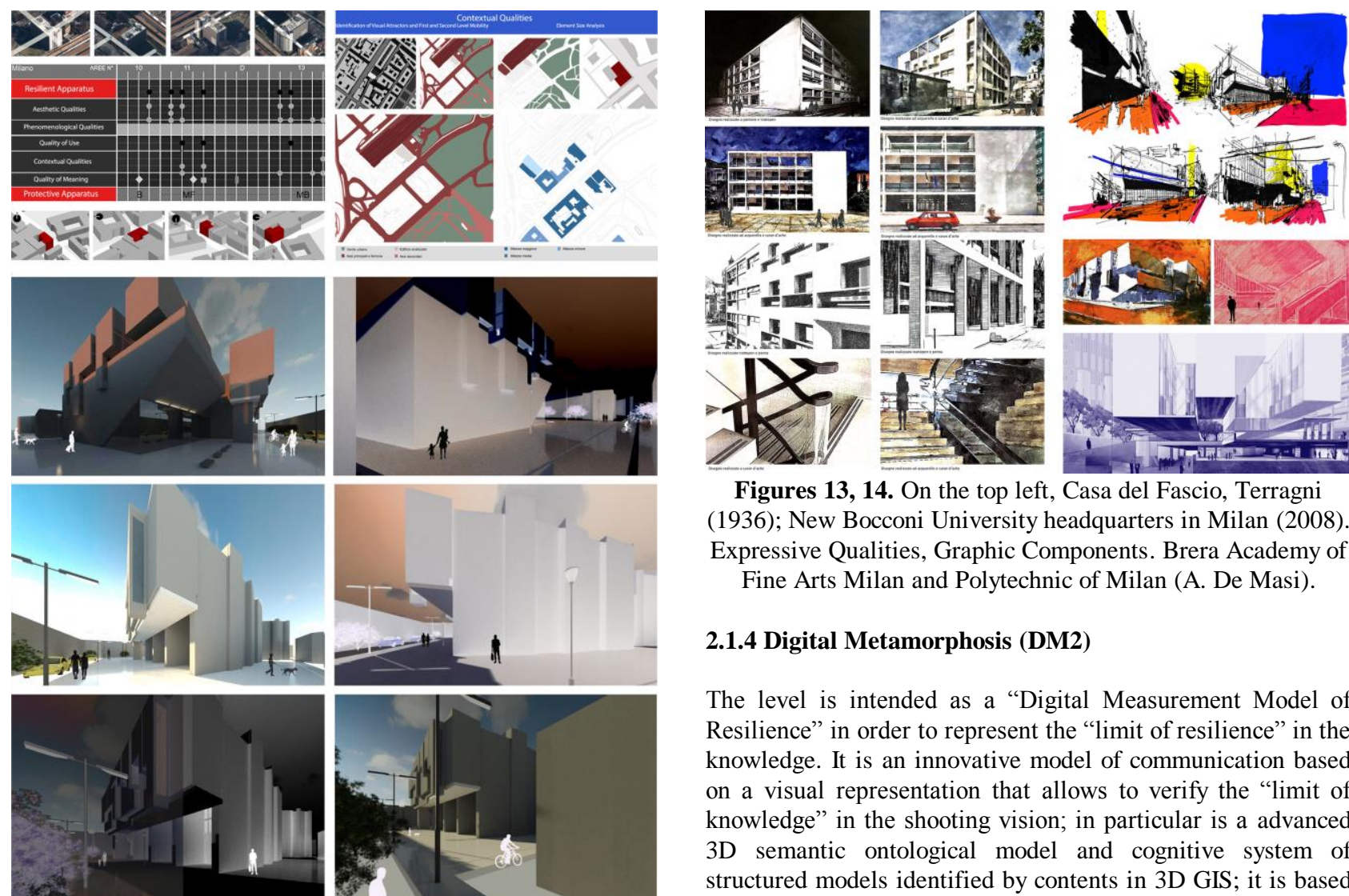

Figure 11. New Bocconi University headquarters in Milan -

Grafton building in via Röntgen (2008). Resilience area:

Resilient models with the elements of visual shooting Brera Academy of Fine Arts Milan (A. De Masi).

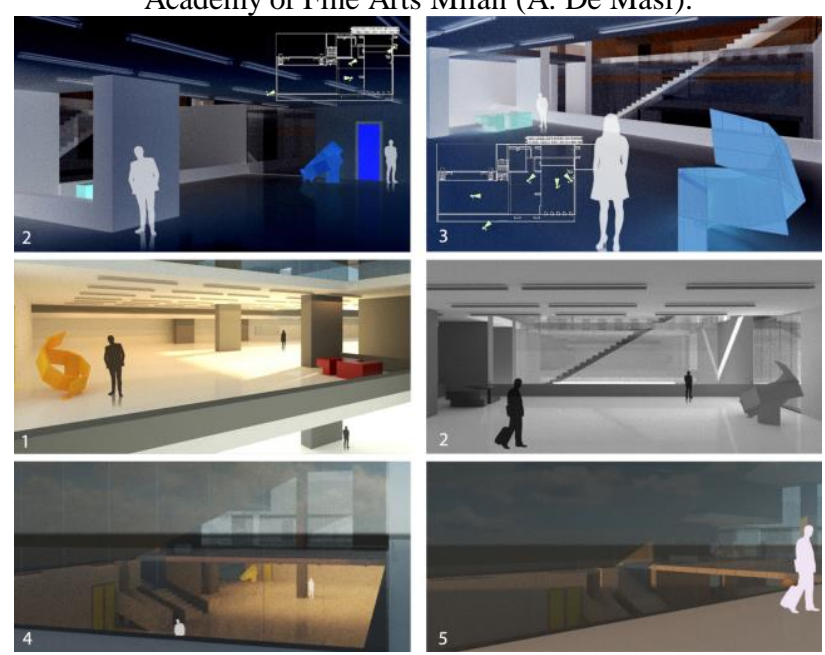

Figure 12. New Bocconi University headquarters in Milan Grafton building in via Röntgen (2008). Resilience area:

Resilient models with the elements of visual shooting. Brera Academy of Fine Arts Milan (A. De Masi).

b) Deconstructivism with design / chromatic innovations, passage to imbalance, chromatic-formal dynamism, to the instability of forms (tortuous, asymmetrical surfaces, sinuous lines, swirling spirals) and the use of primary colors; c) color, light and nature to combine, through design transparencies, shades of gray, light and nature within the projects (see Bauhaus headquarters in Dessau, teaching houses).
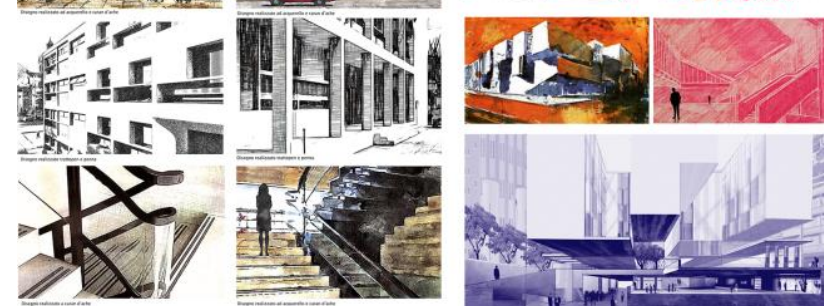

Figures 13, 14. On the top left, Casa del Fascio, Terragni (1936); New Bocconi University headquarters in Milan (2008). Expressive Qualities, Graphic Components. Brera Academy of

Fine Arts Milan and Polytechnic of Milan (A. De Masi).

\subsubsection{Digital Metamorphosis (DM2)}

The level is intended as a "Digital Measurement Model of Resilience" in order to represent the "limit of resilience" in the knowledge. It is an innovative model of communication based on a visual representation that allows to verify the "limit of knowledge" in the shooting vision; in particular is a advanced 3D semantic ontological model and cognitive system of structured models identified by contents in 3D GIS; it is based on creative methodology that starts from the volumetric model to reach the mathematical model on which to realize detailed studies in the project. The methodology remembers that applied by Renaissance architects who, at the initial phase, elaborated drawings for the realisation of wooden-study model. The communication, starting from this design complexity, consists of:

- "Communicative models of Resilience Measurement in Representation" to detail the "limit of resilience" in the knowledge; model representations, in perspective or in axonometric projection relevant for position and size. Spatial understanding is increased by rotation the model and subsequent visualisation in axonometric projection (from top to bottom and from bottom to top) - (De Masi, 2020a). As in the expressionism of "Italian rationalism" of the "Italian Movement for Rational Architecture" (MIAR) of the 1930, where the axonometric vision is understood as the conclusive representation of the design process, comparable to the wooden model, presented with view from top to bottom (to identify with the wooden model of the past), and from bottom to top (replacing accidental perspective representation as it is considered a non-rational visual interpretation) - (De Masi, 2020a). Limited works of MIAR are represented in perspective, as those of Giuseppe Terragni (1904 - 1943), for the understanding of space - (De Masi, 2020a) - (Figure 15).

- "Complex design" thinking in balance between transparent volume, force interpenetration, geometric construction and algorithm that can return a unique expression conclusive in axonometry or perspective. The transparency of the volumes appears in line with orthogonal axonometries elaborated by the German Bauhaus German School of Art (1919-1933) to represent the functionalism of the regular forms of architecture (Figure 16); 
- "Spatial compartment of objects and decomposition of the line-force movement as in the futurist period (De Masi, 2020a). The sensation that comes out is of complex and contradictory forms. In this context are evident the relationship between architectural space and optical illusion, transparent volume and force interpenetration, exaltation of dark tones and a widespread illumination, geometric construction and algorithm (Figure 17).

\subsubsection{Digital Regeneration (DR)}

The level relative at urban landscape with the reconnection of empty spaces to the $\mathrm{CH}$ is based on the following subcategories:

- "Experiments of light and colours" for the creation of innovative chromatic (iridescent, vibrant, changeable, iridescent) and perceptual surfaces, modifying the way of communication of the architectural space and chromatic compositions (De Masi, 2020a, 2020b);
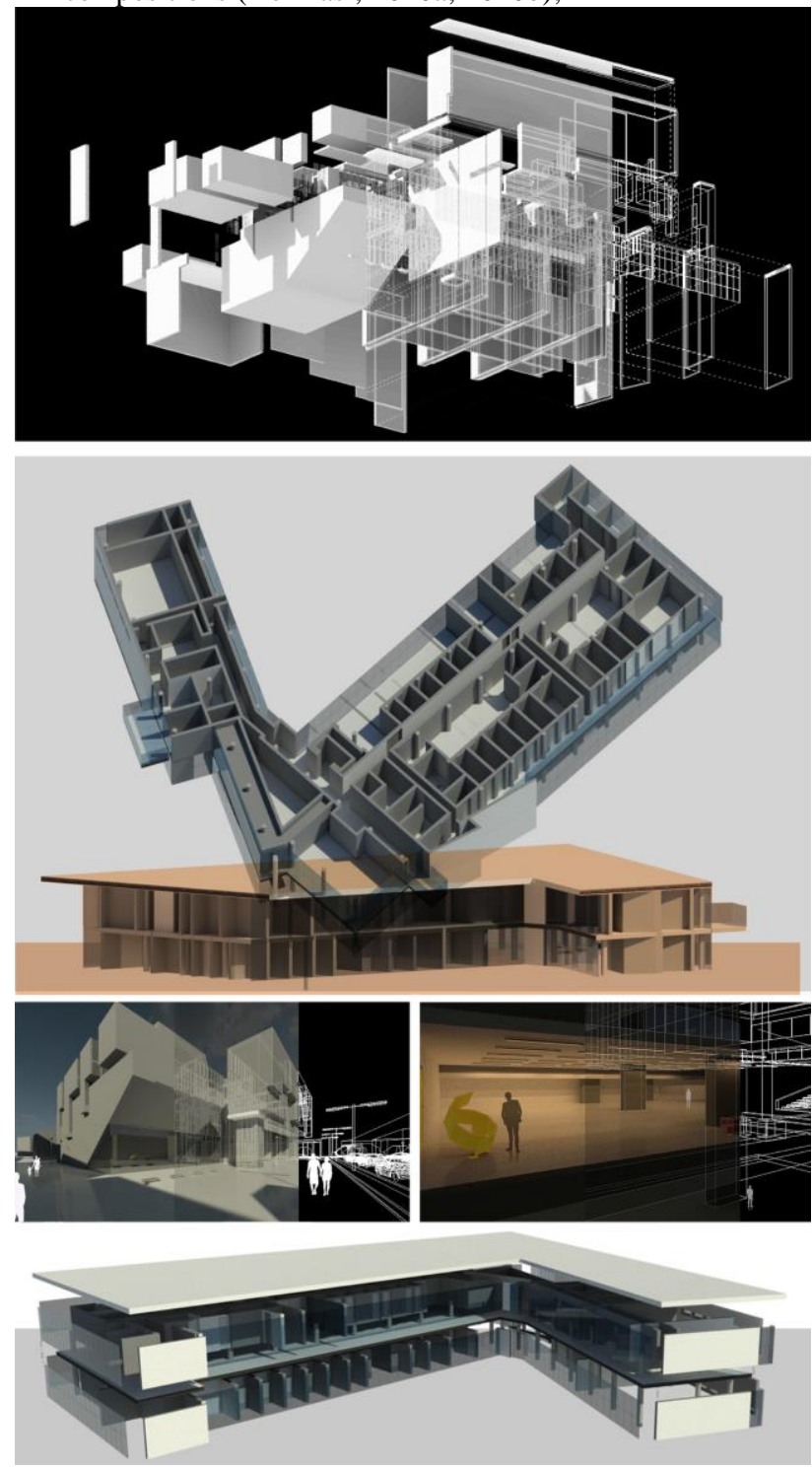

Figures 15, 16. New Bocconi University headquarters, Milan (2008) and ILAB ITALCEMENTI, Bergamo. Digital

Metamorphosis, "Communicative models of Resilience, decomposition of the line-force, Spatial compartment of objects and decomposition of the line-force. Brera Academy of Fine

Arts Milan (A. De Masi).
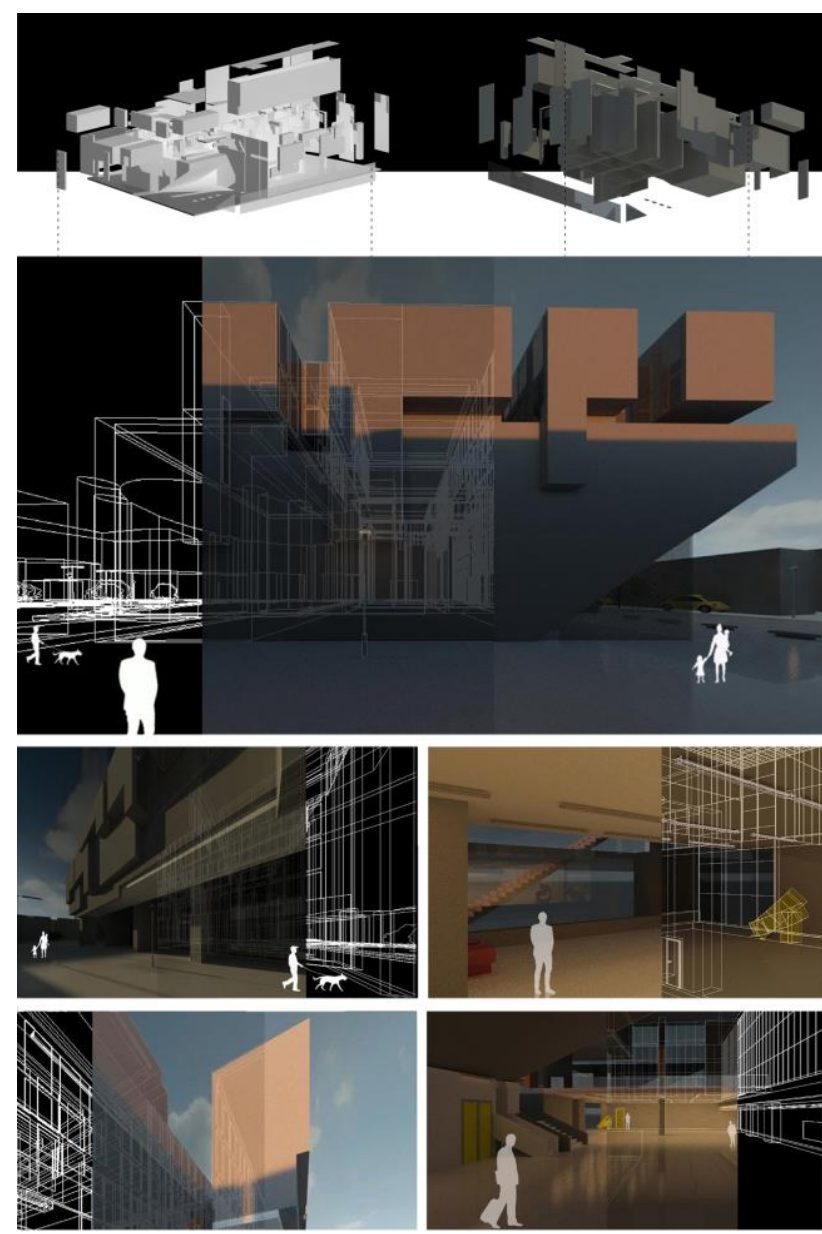

Figure 17. New Bocconi University headquarters in Milan -

Grafton building in via Röntgen (2008). Digital

Metamorphosis, Communicative models of Resilience, Spatial compartment of objects and decomposition of the line-force.

Brera Academy of Fine Arts Milan (A. De Masi).

- "Light effects connected to chiaroscuro ones" for the visual rendering of shapes and profiles given by the combination of pure forms and visual lightness, chromatic uniformity, material transparency;

- "Colour combinations Simulation and Photorealism", based on visual stimuli similar to those produced by reality linked to the: a) variations of luminance through the theory of the tristimulus (light sources, materials and lighting model); b) global illumination through Ray-Tracing models (specular reflections of light) and Radiosity (diffuse reflections between surfaces) - (De Masi, 2020a);

- "Textures combinations Simulation" based on innovative textures;

- "Colour Combinations Post-production" through: Chromatic perception (light / material behavior); Adequate lighting shades (colour rendering index - IRC) to the type of objects and psychological effects; Destination profile through Non Colorimetric Intents (Perceptual - to maintain the colour tint at the expense of brightness and saturation Saturation - to maintain colour saturation at the expense of brightness and tint) and Colorimetric (Relative Colorimeter - modification of the saturation but not the brightness of colours - Absolute Colorimeter - modification of the saturation and brightness of colours); Use of colour / information channels - (De Masi, 2020a) - (Figure 18); 

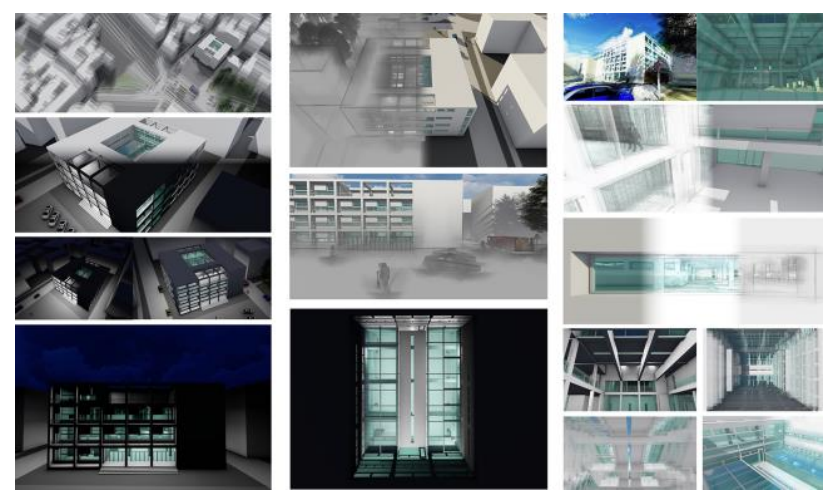

Figure 18. Casa del Fascio, Terragni (1936). On the top left, decomposition of the line-force, exaltation of dark tones and a widespread illumination. Brera Academy of Fine Arts Milan

(A. De Masi).

\subsection{Digital Interaction and Sharing (DIS)}

The level, within the relationship between $\mathrm{AR}$ and $\mathrm{AI}$, is intended as infotainment quantitative and qualitative of cultural informations with benefits for smart working; it is configured as a high informative level of interaction for visual content, that allows to show the potential of $\mathrm{CH}$ and architecture. In fact, through the overlay principle it is possible to allow the system to recognize and activate the integrated communication level for the insertion of three-dimensional elements in real time. Consequently, the immersive experience will allow the amplification of the contents relating to the "ontological digital layers" previously analyzed for $\mathrm{CH}$ or building areas of cultural value. It will provide the assembly of the digital content of some layers (Metamorphosis, Metadata and Regeration) with the categories of augmented reality:

\section{- DP1 - Recognition}

- "Image Segmentation", understood as classification of the pixels within a class; it is articulated through Semantic Segmentation (in which belonging of the images are identified to a specific class, without distinction of the different instances present in the same) and Instance

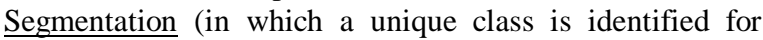
each instance of a particular object);

- "Marker", images made up of characters, qr code or geometric shapes; if framed with a camera, they allow you to view the image or 3D model;

- "Interaction";

- DP2 - Monitoring and management: Point clouds Semantics, Element classification, Hierarchical structures Sensors, Multiscale database of 3D visualization in GIS environment by "Advanced 3D Semantic Ontological Model" with adequate level of accuracy;

- DP3 - Post Digital knowledge (digital, virtual and online technologies, digital image processing) - (Figure 19);

\section{Result and Conclusion}

From the point of view the results and conclusion the study allowed to highlight: a) Digital regenerative synergies of representation for a new digital culture based on scalable, adaptable and resilient digital content in hybrid or semi-hybrid

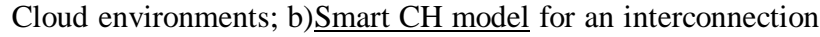
of systems of assets and services within a complex set of relationships; c) Phenomenological reading of the changing complexity of environmental reality; d) Hub solution of
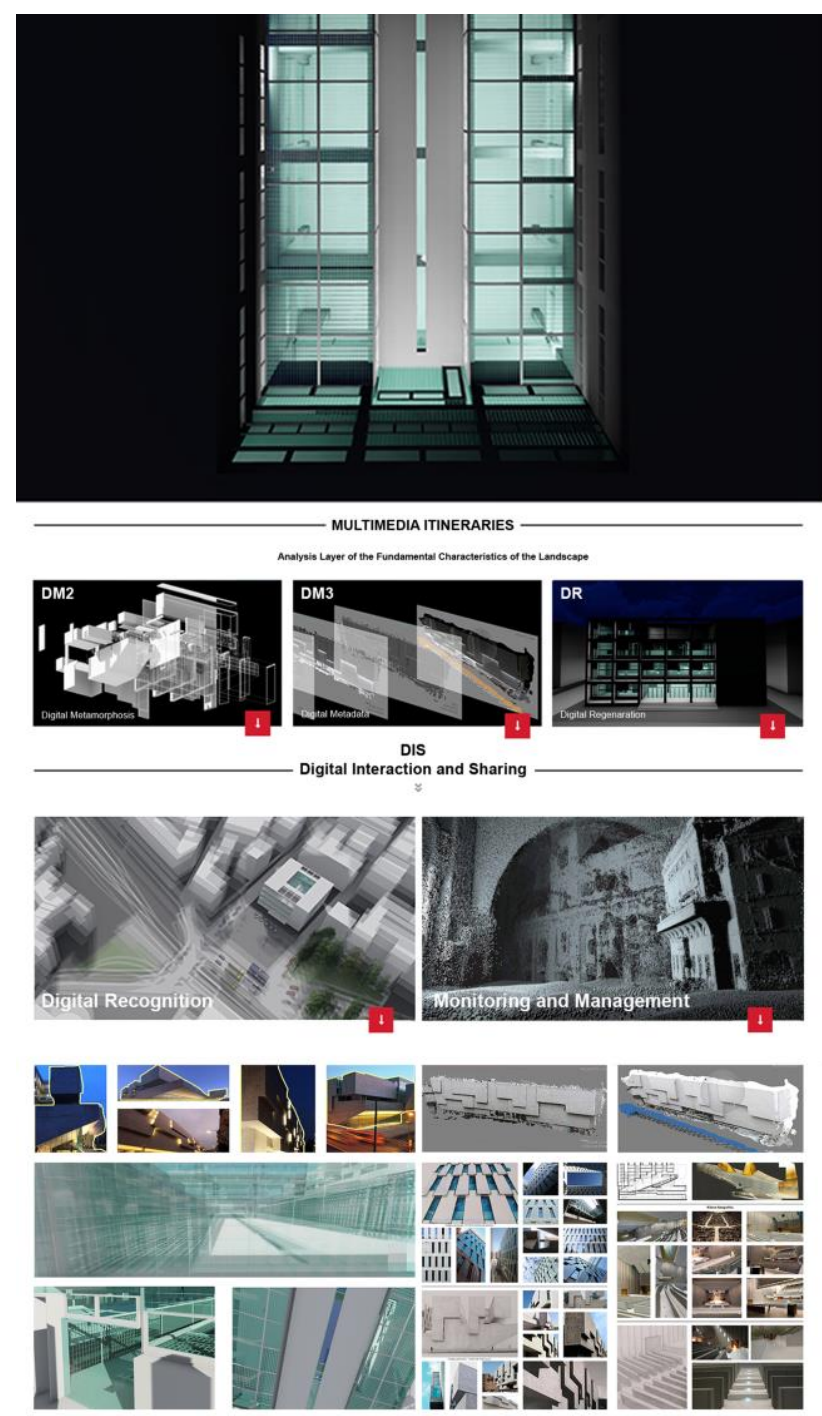

Figure 19. New Bocconi University headquarters in Milan Grafton building in via Röntgen (2008). Service integration host in the Cloud Computing Platform BIM/CHR (A. De Masi).

knowledge and simulcast description of information of $\mathrm{CH}$ connected to a service integration host with transition from parametric representations to objects integrated into 3D Web; e) Multimedia itineraries to enhance participatory and attractive processes for the community; understood as a factor of cohesion and sociality, an engine of local development.

\section{REFERENCES}

Burba G., Resilienza e modelli culturali: un costrutto ambivalente, giovani e comunità localià\# 03 .

Blumauer A., 2014: From Taxonomies over Ontologies to Knowledge Graphs, July 2014 [August, 2016].

Caragliu A., Del Bo C., Nijkamp P., 2009. Smart Cities in Europe. Series Research Memoranda 0048, Free University Amsterdam.

De Chirico, G., 2019: Il Volto della Metafisica, Skira, Milano. 
De Masi, A., 2020a: From Computational De-Morphogenesis to Contaminated Representation for the Contemporary Digital Tectonics and Lexicon. Vulnerability and Resilience of the Generative Representation in the Web-Oriented Platform BIM/GD. In IEE BigData 2020, Volume 1, pp. 1884-1893, IEEE, 10-13 dicembre 2020, Atlanta, GA, USA, DOI:10.1109/ BigData50022.2020.9377781.

De Masi A., 2020b: Computational Color Drawing for Heritage Urban Landscape's Forms Representation: Visual Perception, Aesthetic Theory and Semiotic Interpretation. In Colour and Colorimetry Multidisciplinary Contributions, Vol. XVI B, Edited by Marchiafava V. and Picollo M. Atti della XVI Conferenza del Colore, Bergamo 2020, Gruppo del Colore, Associazione Italiana Colore, pp.240-248, ISBN 978-88-99513$13-9$.

De Masi A., 2020c: Cloud Computing Platform BIM Towards Industry 4.0: De-Morphogenesis and Semantic Ontology. In: Empler, T., Caldarone, A., Fusinetti A. (eds.) 3D MODELING \& BIM Data Modeling \& Management for AECO Industry, DEI, ISBN 9788849619324EB.

De Masi, A., 2019: Strategies of Digital Knowledge's Representation: From De-Morphogenesis at MSH-BIM. Optical, Theatrical illusion and Perspective in the Neapolitan School's Architecture Drawing. Int. Arch. Photogramm. Remote Sens. Spatial Inf. Sci., Volume XLII-4/W18, 2019 www.int-arch-photogramm-remote-sens-spatial-inf-sci.net/XL5-W7/113/2015/doi:10.5194/isprsarchives-XL-5-W7-113-2015. ISSN 2194-9034, https://doi.org/10.5194/isprs-archives-XLII4-W18-305-2019

De Masi, A., 2018: Eco Sustainable Graphic Heritage Drawing for a Contemporary Territories Learning and the creating Smart Cities. In Progress in Cultural Heritage: Documentation, Preservation, and Protection. EuroMed 2018. Lecture Notes in Computer Science, vol 11197, pp 262-270, Springer, Cham.

De Solà M., 2001: Pratiche Teoriche, Pratiche Storiche, Pratiche Architettoniche, Allemandi.

Droste, M., 2021: Bauhaus 1919-1933, Taschen.

Guidelines on Cultural Heritage Technical Tools for Heritage Conservation and Management, European Union, Council of Europe, 2012.

Grimm S., Abecker A., Völker J., Studer R., 2011: Ontologies and the Semantic Web. In: Domingue J., Fensel D., Hendler J.A. (eds) Handbook of Semantic Web Technologies. Springer, Berlin, Heidelberg. doi.org/10.1007/978-3-540-92913-0_13.

Ferrara G., Campioni G., 1997: Tutela della Naturalità Diffusa, Pianificazione degli Spazi Aperti e Crescita Metropolitana, Il verde Editoriale s.r.l., Milano.

Kroetsch M., Weikum G., 2016: Journal of Web Semantics: Special Issue on Knowledge Graphs.

Irace F., 2001: Dimenticare Vitruvio, Ed Il sole 24 ore.

Ingegnoli V., 1993: Fondamenti di Ecologia del Paesaggio: studio dei sistemi di ecosistemi, Città Studi, Milano
Ingegnoli V. 1980: Ecologia e Progettazione, Edizione CUSL, Milano.

Italian Government Presidency of the Council of Ministers, National Recovery and Resilience Plan (PNRR): Next Generation Italia.

Lawrence R., Claudius Jr., Divus, Templum, 2019: A New Topographical Dictionary of Ancient Rome, JHU: Baltimore, MD, USA, p. 87.

Lynch K., 1960: The Image of City, The Technology Press \& Harvard University, Cambridge, USA.

Norberg-Schulz C., 1996: Architettura: Presenza, Linguaggio e Luogo, Skira ed. Milano.

Organizzazione delle Nazioni Unite, Trasformare il nostro mondo: l'Agenda 2030 per lo Sviluppo Sostenibile, Resolution adopted by the General Assembly on 13 September 2005.

Paulheim H., 2016: Knowledge Graph Refinement: A Survey of Approaches and Evaluation Methods. Semantic Web Journal, (Preprint):1-20.

Tafuri M., 1968: Teorie e Storia dell'Architettura, Einaudi Torino. 